\title{
Study of Clinico-Radiological Profile in Childhood Tuberculosis
}

\author{
Triya Malde', Gaurang Pabani ${ }^{2}$, O.P.Shukla ${ }^{3}$ \\ ${ }^{1}$ Assistant professor, Department of paediatrics, M. P. Shah medical college, Jamnagar, India, ${ }^{2}$ Assistant professor, Department of paediatrics, Dr M K Shah Medical \\ College and Research Centre, Chandkheda Ahmedabad, India, ${ }^{3}$ Assistant Professor, Department of Paediatrics, Baroda medical College, Vadodara, India.
}

\section{Abstract}

Background: Tuberculosis still is one of the deadliest diseases in the world killing nearly 2 million people every year. In India, two deaths occur every three minutes from tuberculosis. The actual global disease burden of childhood tuberculosis is not known, as childhood Tuberculosis is notoriously difficult to diagnose because of the absence of a 'gold standard' as bacteriologic confirmation is rarely achieved. The present study was designed to study clinical profile of various forms of childhood TB. Objective of this study was to study clinicepidemiological profile of various forms of childhood TB. Subject and Method: Retrospective analysis of clinical profile of 100 patients of childhood TB in the age group of 6 months to 12 years. A detailed clinical history, family history of contact with Koch's disease, history of BCG vaccination of each child was recorded. A complete examination was carried out and findings regarding the general and systemic examination were recorded. Result: Age distribution in our study showed that $51 \%$ cases in the age of 5-12 years, $47 \%$ cases in the age group 1-5 years and $2 \%$ cases falling in the age group $0-1$ years, with male to female ratio of a 1.27:1. 95\% of the patients belonged to the lower socio-economic class. The distribution of TB was- pulmonary tuberculosis(42\%), TBME(30\%),pleural effusion(12\%), abdominal TB (12\%), TB lymphadenitis( $4 \%)$, Osteotuberculosis (2\%), miliary TB (2\%). $12 \%$ of the patients had mild to moderate malnutrition (PEM Grade I, II)and 57 $\%$ were severely malnourished. $72 \%$ of the patients were BCG vaccinated and history of Koch's contact were present in $21 \%$ of all cases. The most frequently seen symptoms were fever $(88 \%)$, cough $(65 \%)$, weight loss in $50 \%$, anorexia in $35 \%$ of cases and in physical examination cachexia was the most common (50\%) followed by hepatomegaly (40\%), lymphadenopathy (16\%) and Splenomegaly (8\%) of cases. Conclusion: childhood TB is commonly seen in children more than 1 year, lower socioeconomic class and in severely malnourished children.

Keywords: Hepatomegaly, Koch's disease, socio-economic class, Tuberculosis.

Corresponding Author: Dr. Gaurang Pabani, Department of paediatrics, Dr M K Shah Medical College and Research Centre, Chandkheda Ahmedabad, India.

Email: drpiyushpujara@gmail.com

Received: January 2020

Accepted: January 2020

\section{Introduction}

Tuberculosis is known to exist in India for thousands of years. It has been mentioned in Vedas and Ayurvedic Samhitas regarding its clinical feature. In the Mahabharata by Maharshi Ved-Vyas there is mentioned death of Vichitravirya, the son of king Shantanu. He died of TB. The disease was known as 'Rajyakhsma'. [1]

Tuberculosis still is one of the deadliest diseases in the world killing nearly 2 million people every year. ${ }^{[2]}$ Tuberculosis, the only infectious disease to be declared a ' global emergency ' by the WHO, is major cause of death in adult and children worldwide but the brunt is borne by developing countries with $95 \%$ of cases and $98 \%$ of deaths. ${ }^{[3]}$ In India, two deaths occur every three minutes from tuberculosis. ${ }^{[4]}$ Tuberculosis continues to be an important cause of morbidity and mortality for children. ${ }^{[5]}$

As children acquire infection with Mycobacterium tuberculosis from adults in their environment, incidence of tuberculosis in children therefore reflect the ongoing transmission and, indirectly, efficacy of the control program. ${ }^{[6]}$

The actual global disease burden of childhood tuberculosis is not known, but it has been assumed that $10 \%$ of the actual total TB case load is found amongst children. Global estimate of 1.5 million new cases and 1,30,000 deaths due to TB per year amongst children is reported. ${ }^{[5]}$

Childhood Tuberculosis is notoriously difficult to diagnose because of the absence of a 'gold standard' as bacteriologic confirmation is rarely achieved and due to the predominantly paucibacillary nature of childhood TB. Sputum microscopy often the only test available in endemic areas, is positive in less than $10-15 \%$ of children with probable TB and culture yields are usually low (30-40\%). ${ }^{[7]}$ The situation is not helped by the presence of a large number of fairly expensive 'diagnostic tests' such as ELISA, PCR, Quantification etc. because a positive result does not always signify presence of disease and likewise a negative result does not necessarily mean absence of disease. ${ }^{[8]}$

Primarily, diagnosis of childhood TB is based on a very high index of suspicion and subsequent detailed clinical \& laboratory evolution. ${ }^{[9]}$ Though Anti-tuberculosis drugs have been available for fifty years now and efficacy of modern 


\section{Malde et al; Clinica-Radialagical Profile in Childhaad Tulerculasis}

short-course chemotherapy has been proved beyond doubt, considerable morbidity results from late diagnosis or inadequate treatment, lack of compliance and lack of guidelines for stopping treatment.

India had a National Tuberculosis Program (NTP) in place from sixties. In 1992, a joint Government of India / World Health organization review found that despite the existence of the NTP, TB patient did not complete treatment. ${ }^{[10]}$ The WHO recommended treatment strategy for detection and cure of TB is DOTS (Directly observed Treatment Short course. Based on the recommendations of the review, the Revised National Tuberculosis Program (RNTCP), incorporating the internationally recommended DOTS strategy, was developed.

The RNTCP, based on the DOTS, began as a pilot in 1993 and was launched as a national program in 1997. Rapid RNTCP expansion began by 1998 . By the end of $2000,30 \%$ of the country's population was covered, and by the end of $2002,50 \%$ of the country's population was covered under RNTCP. By 2005, around $97 \%$ of the population had been covered, and the entire country was covered under DOTS by $24^{\text {th }}$ March 2006. ${ }^{\text {[4] }}$

The Indian Academy of Paediatrics (IAP) in 1997 recommended standard protocol for treatment of childhood TB. ${ }^{5}$ In Gujarat RNTCP was started in 2000 and patients wise boxes were launched in 2007 . To seek consensus on improved case detection and improved treatment outcomes for all diagnosed paediatrics TB case, a workshop on the "formulation of guideline for diagnosis and treatment of paediatric TB cases under RNTCP" was held in New Delhi in Aug'2003. [5]

Implementation of DOTS under RNTCP for paediatric patients was started in month 2007 at District TB Centre (DTC) in Shri Sayaji General Hospital and Medical College Baroda. There is a total change in the scenario before $\&$ after implementation of DOTS and so this study was undertaken when DOTS was newly introduced in our hospital with a view to find out to study the clinicoradiological profile of patients suffering from pulmonary and extra pulmonary tuberculosis in paediatric age group.

\section{Subjects and Methods}

This study was conducted in the Department of Paediatrics, Shri Sayaji General Hospital and Medical College Baroda, between Oct' 07 to Nov'08 including OPD \& ward patients. The total numbers of 100 patients in the age group 6 months to 12 years were included in this study and all of them presented with clinical features of tuberculosis. This is longitudinal study with simple randomization with sample size of 100 .

\section{Inclusion criteria}

Total numbers of 100 patients in the age group 6month- 12 years were included in this study all of them presented with clinico-radiological features of TB.
Children and infants attending the out patients department between Oct. 07 to April '08 with clinical symptoms and signs suggestive of tuberculosis were enrolled in the study. A detailed clinical history, family history of contact with Koch's disease, history of BCG vaccination of each child was recorded. A complete examination was carried out and findings regarding the general and systemic examination were recorded.

The nutritional status was assessed and classified according to IAP classification of under nutrition. Mantoux test was given to all patients with $10 \mathrm{TU}$ on the left forearm and readings were taken at the end of 72 hours.

Relevant pathological and radiological investigations were done to substantiate the diagnosis of tuberculosis. Patients were classified according to RNTCP guideline for diagnosis of childhood tuberculosis. Then the patients were assigned the category by the concerned paediatrician. Then each patient was referred to district tuberculosis centre OPD (17). DTC enrolment was done and patient was allotted nearest DOTS centre, according to the residential area, either urban (Baroda Municipal Corporation) or rural. From the respective DOTS centre, the patients were examined and enrolled by Concerned Medical Officer. After enrollment Medical Officer will demand drug pouches from Suryanarayan baug - urban TB centre for the enrolled patient. Patients get drug- pouches from their nearest DOTS center. The patient's belonged to rural areas under district of Baroda are being provided drugs by nearest rural DOTS center.

Then regular follow up of the patients was done at frequent interval in paediatric OPD for assessment of improvement or deterioration of general well being and clinico-radiological profile. During this study, frequent visits to DOTS centre were done in rural and urban area, to ensure the provision of drugs to the patients by DOTS provider and to check the compliance of patients under DOTS treatment.

\section{Statistical Analysis}

The recorded data was compiled and entered in a spreadsheet computer program (Microsoft Excel 2007) and then exported to data editor page of SPSS version 15 (SPSS Inc., Chicago, Illinois, USA). Descriptive statistics included computation of percentages, means and standard deviations. For all tests, confidence level and level of significance were set at $95 \%$ and $5 \%$ respectively.

\section{Results \& Discussion}

The present study was carried out in Department of Paediatrics, Shri Sayaji General Hospital, Medical College, Baroda from October 2007 to November 2008 over a period of 13 months. Total 100 patients were enrolled in the study. 
Table 1: Age and Sex Distribution of the Patients Enrolled In the Study

\begin{tabular}{|l|l|l|l|}
\hline Age in year & Male & Female & Total \\
\hline $0-1$ & 1 & 1 & 2 \\
\hline $1-5$ & 24 & 23 & 47 \\
\hline $5-12$ & 31 & 20 & 51 \\
\hline Total & 56 & 44 & 100 \\
\hline
\end{tabular}

Age distribution showed $2 \%$ cases falling in the age group $0-1$ years, $47 \%$ cases in the age group 1-5 years and $51 \%$ cases in the age of 5-12 years. In the study by Anis-ur-Rehman, at Ayub Medical College, Abbottabad, Pakistan, $8 \%$ of the patients were below 3 years and $22 \%$ of the patients belonged to 3-6 years and $48 \%$ of the patients were between $6-12$ years. ${ }^{11}$ Our study showed that TB infection is common in the infancy and preschool age.

\section{URBAN, RURAL, TRIBAL DISTRIBUTION OF THE PATIENTS}

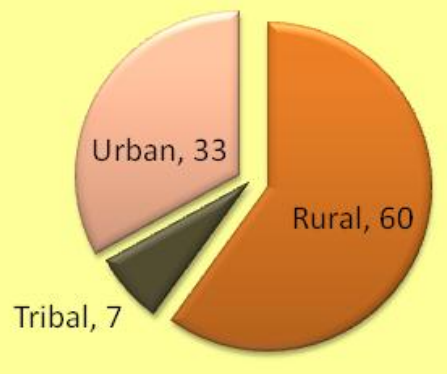

Figure 1: Pie Diagram.

Above table and pie diagram shows that $67 \%$ of the patients hailed from rural area and $33 \%$ were residing in urban areas. Only $7 \%$ hailed from tribal area.

Table 2: Distribution of the Patients According To SocioEconomic Classification (Modified Prasad's)

\begin{tabular}{|l|l|l|}
\hline Socio Economic Status & Number of patients & $\mathbf{\%}$ \\
\hline I & 2 & 2 \\
\hline II & 3 & 3 \\
\hline III & 10 & 10 \\
\hline IV & 50 & 50 \\
\hline V & 35 & 35 \\
\hline Total & 100 & 100 \\
\hline
\end{tabular}

Table 2 shows that $95 \%$ of the patients belonged to the lower socio-economic class of III, IV, V of Modified Prasad's classification. $73 \%$ belonged to lower socioeconomic status in the study of Thilotheammal et al. ${ }^{[12]} \mathrm{High}$ incidence of TB in children aged 0-5 years in an area of South Africa correlated with lower level of parental education, low annual household income. ${ }^{[13]}$ Our study showed that TB is more prevalent in lower socio-economic class.
Table 3: History of Koch's Contact in the Patients Enrolled In the Study

\begin{tabular}{|l|l|l|}
\hline History of Koch's contact & Number & \% \\
\hline Present & 21 & 21 \\
\hline Absent & 79 & 79 \\
\hline Total & 100 & 100 \\
\hline
\end{tabular}

Table 3 shows that the history of Koch's contact was recorded in $21 \%$ children. Schaaf et al. at Baylor College of Medicine, Houston, Texas showed that contact with infectious tuberculosis adult was recorded in $49.5 \% .^{[14]}$

$38 \%$ of the patients had mild to moderate malnutrition \{PEM Grade- I,II \& under nutrition(6-12 years)\} and 27\%(PEM Grade-III,IV) were severely malnourished. Our study shows that $65 \%$ of the patients had malnutrition. Cherry Lyn P. et al at Department of Paediatrics, Philippines, General Hospital, Manila, observed malnutrition in $52.3 \%$ patients in his study(21). Malnutrition decreases immunity in growing children making them more vulnerable to tuberculosis. ${ }^{[15]}$

Table 4: BCG immunisation status of the patients enrolled in the study

\begin{tabular}{|l|l|l|}
\hline Status of BCG Scar & Number & \% \\
\hline Scar present & 72 & 72 \\
\hline Scar absent & 28 & 28 \\
\hline Total & 100 & 100 \\
\hline
\end{tabular}

Table- 4 shows that $72 \%$ patients were immunized with $\mathrm{BCG}$ vaccine and only $28 \%$ did not receive any $\mathrm{BCG}$ vaccine. BCG vaccinated patients had more of osteotuberculosis (100\%), primary pulmonary complex $(88 \%)$, progressive pulmonary disease $(87.5 \%)$, abdominal TB (83\%), TB lymphadenitis $(75 \%)$ and less of complicated TB like TBME (40\%) and miliary $\mathrm{TB}(0 \%)$.

BCG scar was present 37 patients $(88 \%)$ of pulmonary TB out of 42 patients whereas scar was present only in $31(70 \%)$ out of 44 patients of extra pulmonary seriouly ill TB. This difference is statistically significant with $p$ value of less than 0.05. The report on the BCG vaccine trial in Chingleput district of Western Tamilnadu, published in 1999, has been widely misinterpreted, as showing that BCG offers no protection against infection under any epidemiological condition. ${ }^{[16]}$ However, since extra pulmonary forms of tuberculosis and children less than 10 years of age were not included in the assessment the results of this study cannot be extrapolated to the paediatric population.

Table 5: Distribution of childhood TB

\begin{tabular}{|l|l|l|}
\hline Type of childhood TB & Number & \% \\
\hline Primary pulmonary complex & 26 & 26 \\
\hline Progressive pulmonary disease & 16 & 16 \\
\hline Pleural effusion & 8 & 8 \\
\hline TBME & 30 & 30 \\
\hline Abdominal TB & 12 & 12 \\
\hline TB lymphadenitis & 4 & 4 \\
\hline Osteotuberculosis & 2 & 2 \\
\hline Miliary tuberculosis & 2 & 2 \\
\hline Total & 100 & 100 \\
\hline
\end{tabular}


Pulmonary tuberculosis comprised of $42 \%$ cases and extrapulmonary cases comprised of $58 \%$. (Table 5) A retrospective study in Brazil found that among less than 15 years of children, pulmonary $\mathrm{TB}$ was most frequent $(57.8 \%)$. Extra pulmonary TB occurred in $24.4 \%$ cases, while both forms occurred together in $17.8 \%$ (39).

Table 6: Distribution of Non-Pulmonary Childhood TB in Malawi

\begin{tabular}{|l|l|l|}
\hline Extra pulmonary TB & \% in Malawi & \% in our study \\
\hline TB lymphadenitis & 41 & 4 \\
\hline Pleural effusion & 12 & 8 \\
\hline Spinal TB & 10 & 0 \\
\hline Pericardial TB & 7 & 0 \\
\hline Ascites & 5 & 12 \\
\hline Miliary TB & 4 & 02 \\
\hline TBME & 4 & 30 \\
\hline Osteotuberculosis & 1 & 2 \\
\hline
\end{tabular}

A nationwide case finding study in Malawi showed that most common childhood extra pulmonary TB was TB lymphadenitis $(41 \%)$. In contrast our study shows that most common extra pulmonary TB was TBME.

Ussery et al found that of 14,414 paediatric ( $<15$ years of age) cases of TB reported in U.S. between 1985 and 1994, $71 \%$ were reported to have pulmonary disease, while $22 \%$ had extra pulmonary disease. ${ }^{[17]}$

Garg p at Agra showed that pulmonary (52.4\%) and extra pulmonary TB (47.6\%) accounted for almost equal number of cases $(52.4 \%, 47.6 \%)$, which matches with our study. Workload from TB clinic (1966-1999) of major tertiary centre in North India, reported extra pulmonary TB in only $17 \%$ of total cases. Extra pulmonary $\mathrm{TB}$ has been reported among $37 \%$ of newly diagnosed cases of TB from 522bedded community Hospital in America. ${ }^{[18]}$

TBME is significantly seen in younger subjects in contrast to pleural effusion, TB lymphadenitis, Ostoetuberculosis which is seen in older age group. Children less than 5 years old and infected with tuberculosis are at higher risk of developing disease probably due to immature immunity. ${ }^{[19,20]}$ Children under the age of 5 years are at higher risk for developing the tuberculous disease after infection; often develop more severe degree of disease. ${ }^{[21,22]}$ Miller F J W et al at London shown that the life time risk for developing tuberculosis after infection is $43 \%$ in infants, $24 \%$ between $1-5$ years of age and $15 \%$ in adolescents, compared to immunocompetent adult with lifetime risk of $5-10 \%$. $^{[22]}$

\section{Table 7: Symptomatology in Childhood TB}

\begin{tabular}{|l|l|l|}
\hline Symptom & Number & \% \\
\hline Fever & 88 & 88 \\
\hline Chronic Cough > 2 weeks & 65 & 65 \\
\hline Weight loss / Failure to thrive & 50 & 50 \\
\hline Anorexia & 35 & 35 \\
\hline Seizure & 15 & 15 \\
\hline Altered sensorium & 15 & 15 \\
\hline Abdominal distension & 10 & 10 \\
\hline Neck swelling & 3 & 3 \\
\hline
\end{tabular}

It can be seen from table 7 that, the most frequently seen symptoms were fever in $88 \%$, cough in $65 \%$, weight loss in $50 \%$, anorexia in $35 \%$ of cases. Schaaf et al at Baylor college of Medicine, Houstan, Texas, had observed cough in $57.7 \%$, weight loss in $53.4 \%$ and fever in $47.7 \%$ ( 27). Cherry Lyn P. et al at Department of Paediatrics, Philippine General Hospital, Manila had observed fever in $89.6 \%$, cough in $76.1 \%$, weight loss in $50.7 \%$, and anorexia in $44.8 \%$. $^{[15]}$

Quadriplegia was the most common neurological defect observed in $30 \%$, followed by Hemiplegia in $26.6 \%$ patients. $7^{\text {th }}$ nerve was the most commonly involved cranial nerve $(26.6 \%)$ followed by $6^{\text {th }}$ nerve in $6.6 \%$ and $3^{\text {rd }}$ in $3.3 \%$ patients.

Abdominal distension was the most common symptom, present in $83.3 \%$ patients; fever was the next frequent complaint present in $58.3 \%$ patients. $58.3 \%$ patients had Abdominal discomfort, while $50 \%$ had came with history of weight loss.

\section{Table 8: Specrtum of Chest $X$ - Ray Findings in} Childhood TB

\begin{tabular}{|l|l|l|}
\hline Finding & Number & \% \\
\hline Primary Pulmonary Complex (when focus) & 26 & 50 \\
\hline Progressive Pulmonary Diseases & & \\
$\bullet \quad$ Cavitation & 4 & 7.6 \\
$\bullet \quad$ Consolidation & 7 & 13.4 \\
$\bullet \quad$ Atelectasis & 5 & 9.6 \\
\hline Pleural Effusion & 8 & 15.3 \\
\hline Miliary infilterate & 2 & 3.8 \\
\hline
\end{tabular}

The finding of calcified hilar lymph nodes \& calcified paranchymal lesion is known as Ranke complex \{Ghon focus or Primary complex $\}.{ }^{[24]}$ The above table shows that Primary Pulmonary Complex were present in 50\% cases, followed by Progressive Pulmonary Diseases present in $30.8 \%$ cases, and $19.2 \%$ had showed normal chest X-ray. Evidence of hilar lymphadenopathy is seen up to 83 to $96 \%$ in children with primary TB. ${ }^{[24-26]}$ It must be pointed out that over diagnosis of hilar lymphadenitis in childhood with slightly rotated or expiratory films is a common mistake in clinical practice. Thymus, body of manubrium can be mistaken for paratracheal lymphadenopathy.

Table 9: Treatment Category as Per Regimen under Rntcp Regimens in the Study

\begin{tabular}{|l|l|l|l|}
\hline Category & Type of childhood TB & Number & \% \\
\hline Category (I) & PPDs & 16 & \multirow{4}{*}{$76 \%$} \\
\cline { 2 - 3 } & TBME & 30 \\
\cline { 2 - 3 } & Abdominal TB & 12 & \\
\cline { 2 - 3 } & Pleural effusion & 04 & \multirow{3}{*}{$24 \%$} \\
\cline { 2 - 3 } & Osteo Tuberculosis & 02 & \\
\cline { 2 - 3 } & Milliary & 02 & 26 \\
\hline Category (III) & PPC & 04 & \\
\cline { 2 - 3 } & TB lymphadenitis & 04 & \\
\cline { 2 - 3 } & Pleural effusion & \multicolumn{2}{|}{} \\
\hline
\end{tabular}

Above table showed that, $76 \%$ patients were enrolled in the category - (I) under RNTCP regimen and $24 \%$ patient were 


\section{Malde et al; Clinica-Radialagical Prafile in Childhaad Tuberculasis}

enrolled under category (III) under RNTCP regimen. No patients were there in category-II.

Table 10: Other Medications/Therapy Received By the Patients Enrolled In Study

\begin{tabular}{|c|c|c|c|c|}
\hline Medication & $\begin{array}{l}\text { Type of } \\
\text { childhood TB }\end{array}$ & Duration & NO. & $\%$ \\
\hline \multirow[t]{3}{*}{ Steroid(prednisolone) } & CNS TB & 2 months & 30 & 100 \\
\hline & Abdominal TB & 2 months & 12 & 100 \\
\hline & Pleural effusion & 2 months & 08 & 100 \\
\hline \multicolumn{5}{|l|}{ Anticonvulsant Drug } \\
\hline Phenytoin & CNS TB & 3 months & 08 & 26.6 \\
\hline Carbamazepine & CNS TB & 9 months & 07 & 23.3 \\
\hline phenobarbitone & CNS TB & 3 months & 01 & 3.3 \\
\hline \multicolumn{5}{|l|}{ Other Medications } \\
\hline $\begin{array}{l}\text { Drugs for relieving } \\
\text { intracranial tension }\end{array}$ & CNS TB & & & \\
\hline Mannitol & CNS TB & 3 days & 22 & 73.3 \\
\hline Glycerol & CNS TB & 15 days & 14 & 46.6 \\
\hline $\begin{array}{l}\text { Carbonic anhydrase } \\
\text { inhibitors }\end{array}$ & CNS TB & 2 months & 22 & 73.3 \\
\hline Multivitamins & & 2 months & 72 & 72 \\
\hline Iron supplements & & 2 months & 67 & 67 \\
\hline Calcium & & 2 months & 15 & 15 \\
\hline \multicolumn{5}{|l|}{ Surgical Interventions } \\
\hline \multicolumn{5}{|l|}{ Therapeutic } \\
\hline V.P. Shunt & CNS TB & & 14 & 46.6 \\
\hline Exploratory laparotomy & Abd. TB & & 1 & 8.3 \\
\hline $\begin{array}{l}\text { Diagnostic } \\
\text { Pleural tapping }\end{array}$ & Pleural effusion & & 8 & 100 \\
\hline Ascitic tapping & Abd. TB & & 11 & 91.6 \\
\hline FNAC & $\begin{array}{l}\text { TB } \\
\text { lymphandenitis }\end{array}$ & & 4 & 100 \\
\hline
\end{tabular}

Above table shows that; all patients of CNS TB(30 - 100\%), Abdominal Koch's Disease, Pleural effusion had received steroid, (Prednisolone) for $8 \mathrm{wks}$, [6 wks - full dose \& 2 wks - tapering dose] Above table also shows that 8 patients (26.6\%) of CNS TB had received Phenytoin for 9 months \& 7 patients of CNSTB (23.3\%) had received carbemezapine for 9 months \& 1 patient (3.3\%) had received phenobarbitone for 3 months. Among all CNSTB patients, 73.3\% patients had received manitol for 3 days, $46.6 \%$ patients had received glycerol for 15 days \& $73.3 \%$ patients had received Diamox for 2 months for the management of raised intracranial tension. $67.72 \%$ patients had received Multivitamins \& Iron supplements for 2 months.

In surgical intervention; V-P Shunt was inserted in $46.6 \%$ patients for the management of raised intracranial tension. 1 patient of Abdominal Koch's Disease was operated for management of loculated tuberculous Ascitis. Diagnostic pleural tapping was done in $8(100 \%)$ patients of TB pleurits $\&$ diagnostic peritoneal tapping done in $11(91.6 \%)$ patients of Abdominal Koch's disease. FNAC was done in all 4 patients(100\%) of TB lymphadenitis

\section{Conclusion}

Childhood TB is commonly seen in children more than 1 year, lower socioeconomic class and in severely malnourished children. 27\% patients were having severe malnutrition and $72 \%$ patients had BCG vaccination scar. There was association between type of childhood TB and age. Out of 100 patients enrolled in the study 66(66\%) were cured/Improved of the disease, $13(13 \%)$ patients expired and 20(20\%) patients were lost to follow up.

\section{References}

1. Chugh Satish An Overview IMA GFATM RNTCP PPM Project. JIMA Vol-106 March 2008 Pg 176-179.

2. Kabra S.K., Lodha Rakesh, Seth V., Some current concept on childhood TB, Department of Pediatrics, AIIMS, New Delhi, India, Journal of Medicine Research 120, Oct. 2004, PP-387-397.

3. Swaminathan Saumya, Deputy Director, Chetput, Chennai.Indian Journal of Pediatrics, Feb. 2000, Vol. 69, S1S2

4. TBC India Directorate General of Health Service Ministry of Health \& Family Welfare.

5. Dendup T, Dorji T, Edginton ME, Kumar AVM, Wangchuk D, Dophu U, Jamtsho T, Rinzin C, et al. Childhood tuberculosis in Bhutan: profile and treatment outcomes. Public Health Action, 2013; 3(1): 11-14.

6. Seth Vimlesh, Kabra S. K., Essential of TB in Children Pg-109-134, 157-210, 315-323.

7. Marais B.J., Pai M., Specimen Collection Methods in diagnosis of Childhood TB, Indian J. Med. Microbial 2006. 24:249-251.

8. Zombini EV, Carlos Henrique David de Almeida, Fernanda Palma CurveloVilar Silva, ElzaSumie Yamada, Naomi Kawaoka Komatsu, Sumie Matai de Figueiredo, et al. Clinical epidemiological profile of tuberculosis in childhood and adolescence. Journal of Human Growth and Development, 2013; 23(1): 52-57.

9. Suryanarayan H.V., Chadha V.K., National TB Institute, 1998.

10. Chauhan L.S., Arora V.K., Management of Pediatrics TB, under RNTCP. Indian Pediatric 2004, 71: 341-343.

11. Rehman Anis-or, Idris Mahammad, Comparison of Mantoux test with diagnostic BCG in pediatric patients with pulmonary tuberculosis.

12. N. Thilothammal, P.V. Krishna Murthy, Basu K., Ratnam S.R., Tuberculosis Meningitis in children, clinical profile Mortality \& Morbidity of Bactrologically confirmed cases. I.P. Vol. 32, June 1995, Pg 641-646.

13. Van Rie A, Byers N, Gie R, Kunneke M., Zeitsman L, Donald P., Childhood Tuberculosis in an urban Population in South Africa : Burden \& NSK factor : Arch Dis Child 1999;80: 433-437.

14. Schaaf H Simon, Marais B.J., Whitelow Andrew, Anneke C Hesseling, Eleg Brian, Husseg G.D., Donald P.R., BMC Infectious Disease 2007 7:140 1186/1471-2334-7-140.

15. Cherry Lyn. P., Clinical profile of culture proven Tuberculosis cases among filipno Children Aged 30 months to 18 years. Phil Journal Microbial Infectious Disease 2001: 30(4) Pg 133-143.

16. TB Prevention trial, Madras, Trial of BCG vaccine in South India for TB prevention. Indian J. Med. Research 1976, 70: 349-363.

17. Ussery X., Valway Mekwana M., Couthen G., Mecray E., Onorato I, epidemiology of TB among children in th U.S. 1985 to 1994 pediatric Inf. Dis. Journal 1996; 15: 697-704.

18. Garg P., Childhood Tuberculosis in a community Hospital from a Region of High Environmental Exposure in North India. Journal of clinical \& diagnostic Research. Feb '08 Vol: 2 Issue : 1 Page 634638.

19. Smith S., Tacobas R.F., Wilson C.B., Immunobiology of childhood TB a window on the ontology of cellular immunity J. pediatric 1997, 131 16-26.

20. Miller F. J. W, Regional difference in TB in children with special preference to India and West Africa trop Bact. 1973; 3: 66-71.

21. Donald P.R., Child \& TB Problems in the next generation 1999; 353 : 1001-1002.

22. Miller F. J.W., Seal RMO, Taylor M.D., Int. TB. In children; evaluation control, treatment London, Churchill, living stone 1963.

23. Fraser R.G., Pare JAP, Pare PD, diagnosis of disease of chest; Philadelphia, WB Saundrs, 1991; Pg. 882-939. 


\section{Malde et al; Clinica-Radialagical Prafile in Childhaad Tuberculasis}

24. Weber AL, Brid KT, Januwa. ML. Primary tuberculosis in childhood with particular emphasis on changes affecting the Tracho bronchial tree Am J. Roentology 1966; $103:$ 123-132.

25. Kim W.S., Moun W.K., Kim L., Pulmonary turberculosis in children evaluation with CT Ame J. Roentology 1997; 168 : 1005-1009.

26. Leung. A.N., Muller NL, Pineala PR, et. al. Primary tuberculosis in childhood; Radiography Manifestation Radiology 1992; 182: 87-91.

Copyright: (C) the author(s), 2020. It is an open-access article distributed under the terms of the Creative Commons Attribution License (CC BY 4.0), which permits authors to retain ownership of the copyright for their content, and allow anyone to download, reuse, reprint, modify, distribute and/or copy the content as long as the original authors and source are cited.

How to cite this article: Malde T, Pabani G, Shukla OP. Study of Clinico-Radiological Profile in Childhood Tuberculosis. Asian J. Clin. Pediatr. Neonatol.2020;8(1):09-14.

DOI: dx.doi.org/10.47009/ajcpn.2020.8.1.3

Source of Support: Nil, Conflict of Interest: None declared. 